\title{
El concepto de originalidad en el derecho de autor peruano
}

\section{Enrique Cavero Safra *}

\begin{abstract}
En el presente artículo, el autor desarrolla en su totalidad la definición del concepto de originalidad expuesto en la Ley sobre Derechos de Autor. El comentario resulta de suma importancia para determinar si una obra de ingenio se encuentra dentro de la esfera de protección que otorga la mencionada ley. Del mismo modo, el autor presenta las distintas asociaciones que se plantean en la doctrina respecto al concepto de originalidad. Finalmente, esboza una definición de "originalidad" y señala que el grado de protección legal de una obra se encontrará determinado por su grado de originalidad.
\end{abstract}

Abogado. Especialista en Derecho de la Competencia y Propiedad intelectual. Socio de Hernández \& Cía. Abogados. 


\section{El concepto de originalidad en el derecho de autor peruano.}

\section{Introducción.}

El artículo 3 del Decreto Legislativo 822 - Ley sobre el Derecho de Autor, señala:

"Artículo 3.- La protección del derecho de autor recae sobre todas las obras del ingenio ${ }^{1}$, en el ámbito literario o artístico, cualquiera sea su género, forma de expresión, mérito o finalidad.

Los derechos reconocidos en esta ley son independientes de la propiedad del objeto material en el cual está incorporada la obra y su goce o ejercicio no están supeditados al requisito del registro o al cumplimiento de cualquier otra formalidad."

De otro lado, el artículo 2 del mismo Decreto Legislativo define el significado de obra como: "Toda creación intelectual, personal y original, susceptible de ser divulgada o reproducida en cualquier forma, conocida o por conocerse."

Así, a efectos de que una creación califique como obra bajo el Derecho de Autor y, en consecuencia, goce de protección legal, debe tratarse de una creación original. Por ello, la comprensión y delimitación del concepto "originalidad" en el Derecho de Autor es de LA MAYOR importancia. La existencia de originalidad, o su ausencia, determina la existencia o ausencia de protección y, como veremos más adelante, determina también la extensión y medida de tal protección.

En el presente trabajo procuramos esbozar una definición, así como revisar los principales rasgos y características de este importante concepto.

\section{El concepto de originalidad.}

Nuestra Ley sobre Derecho de Autor, el Decreto Legislativo 822, no ha incorporado a nivel normativo una definición de originalidad. A nivel de la jurisprudencia administrativa, la Sala de Propiedad Intelectual del INDECOPI ha establecido el siguiente marco conceptual a través de un precedente de observancia obligatoria:

"Debe entenderse por originalidad de la obra, la expresión (o forma representativa) creativa e individualizada de la obra, por mínimas que sean esa creación y esa individualidad. La obra debe expresar lo propio del autor, llevar la impronta de su personalidad.

$1 \quad$ El énfasis en negritas, en esta y demás citas contenidas en el presente artículo, es añadido nuestro. 
No será considerado individual lo que ya forma parte del patrimonio cultural artístico, científico o literario- ni la forma de expresión que se deriva de la naturaleza de las cosas ni de una mera aplicación mecánica de lo dispuesto en algunas normas jurídicas, así como tampoco será la forma de expresión que se reduce a una simple técnica o a instrucciones simples que solo requieren de la habilidad manual para su ejecución.

En consecuencia, no todo lo producido con el esfuerzo de su creador merece protección por derechos de autor. Igualmente, aun cuando exista certeza de que una creación carente de individualidad ha sido copiada textualmente, tal circunstancia no convierte a ésta en obra." ${ }^{2}$

Así, el INDECOPI, siguiendo a la doctrina mayoritaria, ha adoptado el denominado criterio de "originalidad subjetiva" que, en esencia, significa que las creaciones, a efecto de ser protegidas por el Derecho de Autor, deben reflejar la individualidad de su creador y la impronta de su personalidad.

En esa línea, Lipszyc define la originalidad como "(...) la expresión -o forma representativa- creativa e individualizada de la obra por mínimas que sean esa expresión y esa individualidad. ${ }^{\prime \prime} \mathrm{Y}$ añade:

"En el proceso de creación de una obra literaria se distinguen, básicamente, tres etapas: primero el autor concibe la idea de la obra, luego elabora el plan de su desarrollo, su composición y, finalmente, la expresa. Toda vez que la originalidad de la idea no cuenta, pues no goza de protección considerada en sí misma, una obra puede ser original en su composición o contenido o en su expresión o forma. En el derecho de autor se consideran obras absolutamente originales aquellas que lo son tanto en la composición como en la expresión. ${ }^{\prime \prime}$

Al respecto, Antequera señala que la originalidad de una obra debe entenderse en el sentido de individualidad y no de novedad, pues de lo que se trata es que el producto tenga sus características propias a fin de distinguirlo de otros del mismo género ${ }^{5}$.

Patry, por su parte, resume bien la perspectiva anglosajona que, en esencia, es muy similar desde el punto de vista conceptual, indicando que originalidad "no significa otra cosa que sencillamente 1) el autor no plagió o copió la obra de otro autor y 2) que existe un aspecto material que distingue a la obra de ser una idea. ${ }^{16}$

2 Resolución 0286-1998/TPI-INDECOPI de fecha 23 de marzo de 1998.

3 Lipszyc, Delia, Derecho de autor y derechos conexos, UNESCO/CERLAC/ZAVALÍA, Buenos Aires, 1993, p. 65.

$4 \quad$ Lipszyc, Della, Derecho de autor y derechos conexos, UNESCO/CERLAC/ZAVALÍA. Buenos Aires, 1993, p.70.

5 Antequera Parilli, Ricardo y Ferreyros Castañeda, Marysol. En: Nuevo Derecho de Autor en el Perú, Peru Reporting, Lima, 1996. p. 68.

$6 \quad$ Patry, William, How to Fix Copyright, Oxford University Press, Nueva York, 2011. p. 20. 
Caballero corrobora ello al distinguir entre originalidad y novedad, haciendo énfasis sobre el hecho que la obra original refleja la personalidad del autor. Asimismo, aclara que el concepto de originalidad descarta la existencia de copia:

"El concepto de originalidad no equivale a la novedad, en el sentido de que solo se protege lo inédito, lo nuevo o lo único, como sucede en el caso de las invenciones, en donde la novedad es requisito indispensable para su patentamiento. De hecho, afirmo que la originalidad se satisface plenamente cuando la obra en cuestión refleja de cualquier modo la personalidad del autor que la ha creado, por contener la forma de expresión que este ha elegido. El requisito de originalidad se cumple igualmente por el hecho de que la obra en cuestión no sea copia de otra preexistente. ${ }^{\prime 7}$

En la misma línea, Rogel Vide, citado por Reuperez Azcárate, señala una serie de atributos en los que puede residir la originalidad y, dentro de ellos, "la existencia de una impronta significativa de la personalidad del autor y efectiva creación de valores que llevan a un único original." 8

Por su parte, Fernandez Delpech opina que "La novedad no es condición necesaria, pero la originalidad o individualidad es requisito insustituible, y podríamos decir que una obra es original cuando expresa de alguna manera, en mayor o menor medida, el espíritu creador del autor sobre un tema o una idea, novedosa o no."

Así mismo, Ríos Ruiz señala:

"Para que la obra sea protegida por el derecho de autor, debe constituir una creación intelectual original. Es la manera como el autor concibe el mundo exterior. Basta que no sea copia de otra, que importe un esfuerzo intelectual de características propias y particulares que haya sido producida con el esfuerzo del autor.

En materia de derecho de autor, se exige que la obra sea original. Pero tal originalidad no se entiende como sinónimo de novedad, sino de esfuerzo intelectual por medio del cual el autor concibe el mundo exterior y lo concreta y plasma en una obra imprimiéndoles su sello o impronta personal; por tanto, permite que todos podamos retomar determinado asunto. ${ }^{\prime \prime 10}$

$7 \quad$ Caballero, José, Derecho de autor para autores, Libraria, México, 2004. p. 3.

8 Reuperez Azcárate, Clara, Las obras del espíritu y su originalidad, Reus, Madrid, 2012. p. 121-122.

$9 \quad$ Fernandez Delpech, Horacio. Manual de los Derechos de Autor, Heliasta, Buenos Aires, 2001. p. 28.

10 Ríos Ruiz, Wilson, La propiedad intelectual en la era de las tecnologías, Universidad de los Andes, Bogotá, 2011. p. 27. 
Tenemos entonces que una obra es original cuando no ha sido copiada y consiste en una forma de expresión concreta, fijada en un soporte material, de una determinada idea, de modo que refleja la impronta de la personalidad del autor.

\section{Originalidad y grado.}

Ahora bien, la originalidad no requiere ser absoluta ni mucho menos. De hecho, en la medida que todas las obras del ingenio son de una u otra manera el reflejo o derivación de obras anteriores que les han servido de base o inspiración, podría incluso decirse que todas las obras son, en realidad, sólo parcialmente originales.

En ese sentido, Lipszyc señala:

"para el Derecho de Autor, el término creación no tiene el significado de sacar algo de la nada y la originalidad de la obra no tiene que ser absoluta, por lo tanto no es necesario que la inspiración del autor esté libre de toda inspiración ajena. Las ideas utilizadas en la obra pueden ser viejas $y$, sin embargo, la obra puede ser original pues, insistimos, el derecho de autor admite que la creación intelectual se realice sobre la base de elementos previos. Solo es necesario que la obra sea distinta de las que existían con anterioridad, que no sea una copia o imitación de otra. ${ }^{\prime \prime 11}$

Como apunta Maraví, el problema podría ser más bien, opuesto. Es decir, si entendemos que todas las obras son producto de un ser humano y, por lo tanto, manifiestan en alguna medida un esfuerzo creativo, entonces siempre reflejarían en algo la personalidad y singularidad del autor. En consecuencia, todas las obras podrían ser consideradas originales, convirtiéndolo en un requisito irrelevante. ${ }^{12}$

Sin embargo, es discutible que todo esfuerzo tenga naturaleza creativa y que, por lo tanto, el resultado de cualquier esfuerzo refleje necesariamente la impronta del autor. Al respecto, ha dicho la Sala de Propiedad Intelectual del INDECOPI:

"El requisito de originalidad o individualidad implica que, para la creación de la obra, debe existir un espacio para el desarrollo de la personalidad de su autor. En consecuencia, lo que ya forma parte del patrimonio cultural artístico, científico o literario- no puede ser individual. Igualmente, la originalidad sirve para diferenciar las obras protegidas por derechos de autor de las banales, de la vida diaria, rutinarias. Tampoco puede decirse que una creación es original si la forma de expresión se deriva de la naturaleza de las cosas o es una mera aplicación mecánica de lo dispuesto en algunas normas jurídicas o por lógica o si la forma de expresión se reduce a una simple técnica que solo requiere de la habilidad manual para su ejecución. Sin embargo, de acuerdo a las circunstancias de un caso particular, un pequeño grado de

11 Lipszyc, Delia, Derecho de autor y derechos conexos, UNESCO/CERLAC/ZAVALÍA, Buenos Aires, 1993. p. 66.

12 Maraví, Alfredo, Breves apuntes sobre el problema de definir la originalidad en el derecho de autor, Pontificia Universidad Católica del Perú, Lima, 2010. p. 21. 


\section{creatividad intelectual puede ser suficiente para determinar que la obra sea original o individual. ${ }^{\prime 13}$}

Rodríguez critica la subjetividad del criterio, ya que ésta lo hace, en su opinión, demasiado restrictivo:

"(...) defender un concepto subjetivo de la originalidad en nuestros tiempos parece perder de vista la influencia del desarrollo tecnológico $y$, además, ignora el importante fundamento de la protección de aquellas creaciones que tienen un destacado impacto en la economía. Las obras no requieren expresar lo propio de su autor o depender de un acto personalísimo de creación al punto que quede impresa la personalidad del sujeto, solamente deben revelar un mínimo esfuerzo creativo. La noción de esfuerzo es importante porque reconoce, de forma amplia, la importancia del aporte efectuado para la creación (esfuerzo personal y patrimonial) y la necesidad de generar incentivos para que dicho esfuerzo se siga produciendo permitiéndose la internalización de los beneficios derivados de tal esfuerzo. ${ }^{\prime 14}$

Sin embargo, entendemos que ese mínimo esfuerzo creativo al que se hace referencia es, precisamente, el que determina la existencia de originalidad. Como ya vimos, no se requiere más que 1 ) haya un esfuerzo mínimo y que 2 ) este esfuerzo sea creativo. De lo contrario, nos encontraríamos, en efecto, ante un escenario donde todo esfuerzo, creativo o no, merecería protección legal, con lo cual se desnaturalizaría el propósito de incentivar, precisamente la creatividad. No todo resultado del esfuerzo será original, dado que no todo esfuerzo tiene naturaleza creativa o innovadora. ${ }^{15}$

Halpern, desde la perspectiva anglosajona, se pronuncia en la misma línea, aunque con una leve diferencia en la terminología, citando el caso Feist Publications, Inc. v. Rural Telephone Service Co., Inc., en el cual la Corte Suprema de los Estados Unidos establece con claridad que "original" significa simplemente que la obra ha sido creada independientemente por su autor (es decir, que no ha sido copiada) y que posee cuando menos un nivel mínimo de creatividad, por lo que el requisito constitucional de originalidad implica o contiene un requisito adicional de "creatividad". Ello, sin dejar de notar que el nivel requerido de creatividad es bastante bajo, de modo que es suficiente un mínimo del mismo. ${ }^{16}$

13

14 Disponible en: http://enfoquederecho.com/original-pero-\%C2\%BFactual-sobre-el-conceptode-originalidad-en-el-derecho-de-autor/, consultado el 30 de agosto de 2015, Enfoque Derecho.

15 Ello no significa que excepcionalmente la ley no pueda proteger el resultado del esfuerzo no necesariamente creativo, como ocurre con algunos derechos conexos.

16 Halpern, Sheldon W, Fundamentals of United States Intellectual Property Law: Copyright, Patent, Trademark, Segunda Edición, Kluwer Law International, The Netherlands, 2007. p. 51-52. 
Al respecto, dice Otero Lastres:

"En cuanto a la "originalidad", si es así que consiste en una cualidad de la obra consistente en que refleja que ha sido fruto de una capacidad creativa de un autor especialmente dotado para el buen ejercicio de la concepción intelectual y de la ejecución material de la obra, es claro que ni todas las obras poseen, sin más, originalidad, ni todas las que son originales muestran el mismo grado". ${ }^{17}$

Emery, por su parte, señala que "se protege la obra con prescindencia de su extensión y calidad, siempre y cuando su forma de expresión tenga un mínimo de originalidad y novedad"18. Y, citando jurisprudencia argentina sobre la materia, indica que "siempre que el trabajo implique un esfuerzo intelectual con un mínimo de expresión personal del autor, ya sea en su contenido, en su plan de desarrollo, en su presentación, o en su recopilación, la obra es protegida $(. . .)^{\prime \prime}{ }^{19}$

Así, no es necesario que la originalidad se presente en grado superlativo y menos absoluto ya que toda obra, de una u otra manera, se nutre siempre de elementos contenidos en trabajos anteriores. Es factible que un pequeño aporte refleje la impronta del autor, siempre que este aporte sea de naturaleza creativa, estableciendo un vínculo de pertenencia autor-obra que determina que la obra se encuentre protegida.

Cabe notar que, si bien se requiere una medida de originalidad mínima, que es la que determina la existencia o ausencia de protección, no existe una medida predeterminada para ello. Significa simplemente el mínimo suficiente para que la obra refleje loa impronta de su autor, lo cual, como vemos más adelante dependerá de cada tipo de obra y deberá establecerse en cada caso particular.

Así, en toda controversia sobre derechos de autor, la originalidad delimitará el objeto de protección:

"(...) la Autoridad Administrativa, en una denuncia por infracción al Derecho de Autor, debe evaluar si ésta se sustenta en la protección de los elementos originales de una creación o no, ya que si lo que se pretende proteger son elementos no originales o ideas, aun cuando estos formen parte de una obra, la denuncia deberá ser declarada improcedente". ${ }^{20}$

Es en la medida, mayor o menor, de originalidad que tenga una obra que ésta gozará de protección. A mayor originalidad, será mayor el ámbito de su protección, es decir, de su derecho de exclusiva. Así, por ejemplo, una obra que esté compuesta por una parte

Otero Lastres, Jose Manuel, "La originalidad de las obras plásticas y las nuevas tecnologías". En: Revista Jurídica del Perú, Número 86, Año 2008, p. 415.

Emery, Miguel Angel. Propiedad Intelectual, Astrea, Buenos Aires, 2009. p. 18.

CNCiv, Sala C, 9/6/78, ED, 81-171.

Resolución 1776-2008/TPI-INDECOPI de fecha 17 de julio de 2008. 
importante o mayoritaria de elementos genéricos o comunes, pero que tiene un grado mínimo de aporte creativo, será una obra original y estará protegida, con un derecho de exclusiva a favor del autor, en la medida o grado de su originalidad. Eso significa que otros podrán utilizar los mismos elementos genéricos para otras obras, pero no podrán utilizar aquello que es original. Si la obra tiene $80 \%$ de elementos genéricos, otros autores podrían crear obras que sean hasta $80 \%$ similares, pero el $20 \%$ que constituye el aporte creativo del autor le pertenece de forma exclusiva, por lo que otros autores no podrán reproducir la obra al $100 \%$. Asimismo, ese $20 \%$ que constituye el aporte creativo, podrá ser, en determinadas circunstancias, protegible de forma separada, como obra independiente.

\section{Originalidad y novedad.}

Como hemos visto, es frecuente que la doctrina, al momento de definir la originalidad en el Derecho de Autor, lo haga diferenciándola del concepto de novedad, propio del derecho de patentes. Asimismo, es frecuente encontrar referencias al criterio de originalidad como "subjetivo" y al de novedad como "objetivo". Es importante tener en cuenta algunas consideraciones, a efectos de comprender esta comparación en su justa medida.

En derecho de patentes, existe lo que se denomina "estado del arte" o "estado de la ciencia", una especie de "dominio público" científico, que contiene todos los avances conocidos o divulgados hasta un determinado momento. Solamente se puede patentar aquello que es nuevo, o novedoso, en el sentido de que no ha sido aún divulgado y, por lo tanto, no pertenece aún al "estado del arte". Si una invención ha sido divulgada, incluso por el propio inventor (por ejemplo si se fabrica o comercializa públicamente, o se publica en una revista científica) antes de solicitarse la patente, la invención pasa a pertenecer al "estado del arte" y deja automáticamente de ser patentable. Todo esto va de la mano con el hecho de que el sistema de patentes es un sistema en el que el registro es constitutivo de derechos y que, en cierta forma, protege las ideas, a diferencia del Derecho de Autor, que protege la expresión material de las mismas y en el cual el registro no es constitutivo de derechos. Debido a todo lo anterior, en realidad, los conceptos de originalidad y novedad no son comparables, al menos en términos homogéneos. Si hacemos una comparación, debemos tener en cuenta que se trata de categorías e instituciones distintas. Analicemos entonces, en ese contexto, las diferencias entre originalidad y novedad.

\section{Originalidad y novedad extrínseca.}

En primer lugar, una invención que ha sido divulgada no puede ser patentada. Una obra divulgada, en cambio, si puede estar protegida por el Derecho de Autor. En el caso de las "obras de arte aplicado", que son protegibles por el Derecho de Autor y también por patentes de diseño, como "diseños industriales", la divulgación perjudica el segundo tipo 
de protección, pero no el primero. Una obra de arte aplicado o diseño industrial que ha sido divulgada ha perdido novedad pero no ha perdido originalidad. En ese sentido, la originalidad es una característica intrínseca (depende de la naturaleza de la obra misma) mientras que la novedad es una característica extrínseca (depende de una circunstancia ajena a la obra, como es su divulgación).

\section{Originalidad y novedad intrínseca.}

En segundo lugar, cabe hacer la pregunta: ¿Si una obra es original e individual, entonces, no será, también, novedosa? Dado que toda obra, como forma de expresión, refleja la impronta y personalidad de su autor y tiene, en consecuencia, carácter individual, entonces debería ser también novedosa, ya que no podríamos encontrar otra obra idéntica o, si encontramos otra obra idéntica, ello significaría que la obra no es original, ya que no refleja la individualidad del autor.

Aquí, la respuesta, en principio, es que, en efecto, si una obra es original (en el sentido de expresión individual) no debería existir otra obra anterior e igual. En consecuencia, en este sentido, originalidad o individualidad vienen a ser lo mismo que novedad. Sin embargo, el Derecho de Autor, precisamente por utilizar el criterio subjetivo (que no sea copia) en lugar del objetivo (que no exista una obra idéntica) permite una excepción a la regla: la creación independiente. Existe la posibilidad de que dos distintos autores, a partir de una misma idea y utilizando los mismos recursos, puedan terminar creando obras muy similares o incluso idénticas, especialmente tratándose de determinado tipo de disciplinas, como por ejemplo la música o la fotografía.

\section{Originalidad y novedad en la idea.}

En tercer lugar, cabe notar que "novedoso" o "nuevo" puede ser entendido como "inédito", sin precedentes. Ello, en razón de la particular naturaleza de la propiedad intelectual en el mundo de la tecnología. Las patentes de invención protegen una solución determinada para un problema determinado, es decir, una combinación del "qué" y el "cómo", donde el "cómo" tiene carácter tecnológico o científico y debe representar un avance significativo. Por contraste, en Derecho de Autor lo que importa no es tanto el "qué", sino el "cómo" y éste no tiene carácter científico o técnico, sino creativo o artístico. Una obra puede tener el mismo motivo o basarse en la misma idea que una obra anterior (el "qué") e, incluso, haber sido ejecutada con los mismos recursos (el "cómo") y sin embargo, ser original, en la medida que el autor ha plasmado su personalidad.

No se trata entonces de que la obra protegida deba ser novedosa en el sentido de algo que "nunca se hizo antes", sino original en el sentido de que "nunca se hizo asi", donde "así" significa no sólo la utilización de los mismos recursos, sino una forma de expresión individual que refleja la impronta de la personalidad del autor.

En esa línea, Françon explica: 
"Para explicar las diferencias entre novedad y originalidad, nos podemos guiar de los siguientes ejemplos: Imaginemos dos pintores que se colocan en el mismo sitio, pintando cada uno un cuadro que representa el paisaje. La segunda tela no es nueva puesto que el mismo tema ha sido ya desarrollado por el otro pintor; pero es original y queda protegida por el derecho de autor, porque la hechura de la obra refleja la personalidad del artista". ${ }^{21}$

Si se asumiera el criterio "novedoso" indicado, en lugar de incentivar a los potenciales autores de nuevas obras para elevar las tasas de innovación cultural, tendríamos como efecto exactamente lo contrario, porque habiendo ilimitadas formas de expresar, cultural o artísticamente, una idea dada, el Derecho de Autor sólo protegería a la primera de ellas.

Al respecto, dice Maraví:

"(...) el Derecho de Autor tiene, como uno de sus objetivos, el fomentar el desarrollo cultural mediante los derechos de explotación que se otorgan sobre la obra y, al ser más restrictivo este criterio, este objetivo no se cumple. Por ejemplo, ante dos fotógrafos que toman fotografías artísticas al mismo paisaje solamente el primero de ellos sería protegido ya que el segundo no tendría una obra totalmente novedosa(...).

De este modo, bajo la teoría de la originalidad subjetiva, dos personas podrían, independientemente realizar la traducción del mismo libro pero, como por cada palabra en un idioma, usualmente existe más de una palabra equivalente en otro idioma, ambas traducciones tendrían diferencias que se explicarían en la selección aplicada por los traductores. Esa selección estaría reflejando la individualidad del traductor, es decir por qué a su criterio pensó o sintió que una palabra era mejor que la otra para traducir el mensaje del autor de libro". 22

Así, la originalidad implica el aporte personal del autor, que éste haya empleado una forma de expresión para materializar una o más ideas. La forma de expresión debe ser original en el sentido que lleva la impronta del autor, pero las ideas que le sirven de base no requieren ser novedosas.

\section{Originalidad, mérito, valor y utilidad.}

Cabe notar que la originalidad es un factor diferente, ajeno e independiente del mérito o valor artístico o de cualquier otro tipo. El criterio subjetivo de originalidad consiste básicamente en que la obra refleje la personalidad o impronta del sujeto-autor (de ahí su carácter "subjetivo"). Ello no debe confundirse ni malinterpretarse en el sentido de que la existencia o inexistencia de originalidad pueda depender de una evaluación subjetiva por

21 FRANÇON, Andre, La propriere litterarie, PUF, Paris, Segunda Edición, 1979. p. 10.

22 MARAVÍ, Alfredo, Breves apuntes sobre el problema de definir la originalidad en el derecho de autor, Pontificia Universidad Católica del Perú, Lima, 2010. p. 19. 
parte del juzgador o de cualquier tercero, respecto al mérito artístico o el valor económico o finalidad. Tampoco es una cuestión de buen o mal gusto. Ello nos conduciría al absurdo de una subjetividad entendida como arbitrariedad, cosa que el ordenamiento jurídico, en general, rechaza. Al respecto, aunque el Decreto Legislativo 822, como hemos visto, no define el concepto de originalidad, si se pronuncia en su artículo 30 , indicando que la protección de una obra es independiente de su género, forma de expresión, mérito o finalidad.

Ya en 1903, el magistrado de la Corte Suprema de los Estados Unidos, Oliver Wendell Holmes Jr., explicaba los problemas que traería el otorgar a los jueces la facultad de evaluar de forma subjetiva, en el sentido de arbitraria, el mérito de una obra como condición para otorgarle protección legal:

"sería una tarea peligrosa para personas entrenadas sólo en leyes el convertirse en jueces definitivos del valor de ilustraciones pictóricas, más allá de los más estrechos y más obvios límites. De un extremo, algunas obras geniales serían con seguridad despreciadas. Su misma novedad las podría hacer repulsivas hasta que el público aprenda el lenguaje que habla el autor. Es bastante dudoso, por ejemplo, que los trabajos de Goya o Manet hubieran sido objeto de protección al ser vistos por vez. Del otro extremo, la protección sería también negada a las obras destinadas a un público menos educado que el juzgador". 23

En la misma línea, explica Saiz García:

"(...) no se trata, pues, de elaborar un juicio estético sobre la obra (...) sino de determinar en qué casos la actividad creativa que conduce a la obra es jurídicamente relevante (...) El derecho de autor protege la actividad intelectual de carácter creativo de todo autor, en cuanto esta conduce a un resultado original perceptible por los sentidos $y$, ello, con independencia del mérito, altura estética o creativa que ella posea. También la creación más pequeña debe tener acceso a la protección" ${ }^{24}$

El orden jurídico, como es natural, proscribe la idea de que la protección legal pueda estar librada a la apreciación arbitraria de alguien con relación a lo que es o no es "artístico" o a cualquier otro criterio similar. Si la protección dependiera del mérito, belleza o valor artístico, según los gustos o particular apreciación del juzgador, el registrador, la autoridad o incluso los usuarios, entonces la protección sería completamente impredecible y, por ende, sus efectos económicos y jurídicos quedarían totalmente distorsionados. La función económica del derecho de autor consiste en crear incentivos suficientes para que los potenciales creadores e innovadores decidan, en efecto, crear e innovar. ${ }^{25} \mathrm{Si}$ la protección

23 BLEISTEN V. DONALDSON Lithographing Co., 188 U.S. 239, 251 -252 (1903)

24 Saiz García, Concepción, Objeto y sujeto del derecho de autor, Tirant Lo Blanch, Valencia, 2000. p. 39.

25 Cavero, Enrique, Entre el huevo o la gallina y la planchada o la camisa - Introducción al Análisis Económico de la Propiedad Intelectual, THEMIS, Lima PUCP, Diciembre 2012. 
estuviera librada a la subjetividad de terceros, ese incentivo sería completamente incierto y, como ocurre casi siempre que se introduce el factor de arbitrariedad en el otorgamiento de derechos, generaría más bien incentivos para la corrupción.

Así, explica Antequera:

"(...) la tutela legal es independiente del género o modalidad creativa (v.gr.: literaria de ciencia o de ficción, plástica pura o aplicada, musical, escénica, informática); de la forma de expresión (v.gr.: a través de signos, palabras, sonidos o imágenes); de su mérito (porque la valoración de la obra no le corresponde a la ley, sino a la crítica); o de su destino (v.gr.: creada para ser divulgada o para permanecer inédita; utilizada para expresar su contenido estético o con el fin de promocionar un producto comercial)." 26

En la misma línea, Lipszyc señala que son ajenos al reconocimiento de protección el valor, destino, o forma de expresión:

a) "El valor cultural o artístico de la obra, su mérito no cuenta para que se beneficie de la protección que acuerda el derecho de autor. Se trata de una cuestión de gustos cuya consideración corresponde al público y a la crítica, no al derecho. Lo contrario podría dar lugar a toda clase de arbitrariedades (...)

b) La obra se encuentra protegida con independencia de que esté destinada a un fin cultural o utilitario. Esta cuestión interesa particularmente en materia de obras de arte o ciencia aplicadas al comercio o a la industria. El hecho que un dibujo o cualquier otra obra artística hayan sido realizados con destino a la actividad comercial o a la actividad industrial, no los priva de la protección que les otorga el derecho de autor contra la reproducción, y, en general, contra la utilización no autorizada. La cuestión también se ha planteado en relación con las guías, catálogos, almanaques, anuarios, nomencladores, las frases y eslóganes publicitarios, las recopilaciones de recetas de cocina, los anuncios, prospectos, circulares comerciales, cuadros sinópticos, que pueden tener, indistintamente, fines culturales, científicos, comerciales o financieros. Lo mismo ocurre con los programas de ordenador, que casi siempre tienen un fin utilitario.

c) Tampoco importa la forma de expresión de la obra. A los fines de la protección del derecho de autor no tiene efecto alguno que la obra sea expresada en forma escrita u oral, que haya sido representada o bien fijada sobre una cinta sonora o audiovisual. Tampoco interesa la forma en que la obra es difundida o comunicada al público."27 
Una razón adicional para la necesidad de evitar la subjetividad en el Derecho de Autor es la misma razón por la cual se proscribe la censura: Normalmente las más innovadoras y frecuentemente las más geniales obras literarias artísticas y obras del ingenio en general, al igual que las opiniones, tienden a ser rechazadas de primera intención por las mayorías, por los defensores y beneficiarios del status quo, los expertos y las voces autorizadas ${ }^{28}$.

Así, es importante tener claro que el criterio de originalidad es subjetivo en el sentido en que se relaciona íntimamente con el autor-sujeto, pero no es, ni debe ser visto como subjetivo en el sentido de arbitrario. Siendo la obra el resultado de un proceso creativo, puede decirse que hay una relación causa-efecto entre autor y obra. La obra es resultado del esfuerzo creativo del autor y por lo tanto contiene y/o refleja la impronta de éste. Ese criterio "subjetivo" al ser una cuestión de hecho debe ser determinado de la manera más objetiva posible.

\section{Originalidad, cuestión de hecho.}

Hemos dicho que la originalidad es un criterio subjetivo en el sentido de que consiste en una relación causa-efecto entre un sujeto y un objeto, pero, al mismo tiempo, puede $-\mathrm{y}$ debe- ser considerada de modo objetivo en el sentido de que se trata de una cuestión de hecho. En efecto, si el aporte creativo existe o no existe, aunque sea de forma mínima, es una cuestión fáctica. Y si tal aporte creativo existe, la protección legal (así como su amplitud o medida) se sigue como consecuencia, es decir, como cuestión de derecho.

Más aún, la originalidad, como cuestión de hecho, se presume, como bien apunta Ferreyros Castañeda:

"(...) siendo la originalidad una cuestión de hecho, el análisis de esta solo debe producirse cuando se encuentre en cuestionamiento. Por ello es que quien alega la inexistencia de originalidad de la obra debe acreditar dicha circunstancia y corresponde su determinación a la plena y razonada decisión de la autoridad, sea administrativa o judicial". ${ }^{29}$

En efecto, siendo que la originalidad implica, en suma, que la obra no es copia y contiene un aporte creativo (es decir, que no consiste completamente de elementos genéricos 0 comunes) solicitar que el autor demuestre la originalidad sería exigirle la probanza de hechos negativos. Quien cuestiona la originalidad debe, más bien, demostrar que se ha producido una copia o que la obra está compuesta completamente de elementos comunes o genéricos.

Ello implica, evidentemente, que la originalidad no pueda apreciarse de la misma manera en todas las obras, sino que se debe evaluar cada caso en concreto, como anota Lipszyc:

28 Ver al respecto Hustler Magazine, Inc. v. Falwell; 485 U.S. 46.

29 Ferreyros Castañeda, Marisol, "La etérea aspiración del plagiario: la originalidad". En: Revista Jurídica del Perú, Número 86, Año 2008, p. 426. 
"La determinación de si una obra es original constituye una cuestión de hecho. La originalidad no puede apreciarse de la misma manera en todas las obras: en materia de obras científicas o técnicas que en relación con las obras literarias de ficción; en composiciones de música popular que en obras sinfónicas; en obras originarias que en obras derivadas". ${ }^{30}$

En sentido similar se pronuncia Otero Lastres:

"Pero chay que entender la originalidad siempre en un único y mismo sentido con independencia de la clase de obra de que se trate? O preguntado de otro modo: chay que entender la originalidad de la obra literaria de la misma manera que la de la obra científica y la de la obra artística igual que la de las otras dos? La respuesta no es fácil, pero, en mi opinión, hay que contestar negativamente. Aunque en los tres tipos de obras la originalidad presenta notas comunes, las diferencias que tienen entre sí los procesos de creación de las obras literarias, las científicas y las artísticas, impiden que se pueda hablar de un requisito con idéntico contenido en todas ellas" ${ }^{\prime \prime 1}$.

Plaza, por otro lado, pone de relieve que la originalidad puede ser de "forma" y no necesariamente "de fondo", en el sentido que se deriva no necesariamente de la expresión de las ideas, sino de la ordenación de éstas ${ }^{32}$ :

"Si bien existen obras cuyas características solo permiten apreciar una única clase de originalidad, ya sea en la expresión de las ideas, ya sea en la ordenación de las mismas, ambas clases de originalidad pueden confluir en una misma obra; si bien basta con acreditar la existencia de una única clase de originalidad para que la obra sea protegible.

En definitiva, el presupuesto básico para que una obra pueda ser catalogada de original es que las ideas puedan ser expresadas o/y ordenadas de distintas formas y el autor haya utilizado una de esas formas de expresión, lo que supone, en el fondo, un 'esfuerzo intelectual individualizado' o 'aportación personal del autor' dignos de tutela jurídica."

Siendo válida, a nuestro criterio, la observación de Plaza, no debe perderse de vista que la originalidad requiere siempre involucrar un esfuerzo creativo y no simplemente un esfuerzo. En ese sentido, parte de la evaluación de la originalidad consistirá en analizar dicho aspecto.

30 Lipszyc, Delia, Derecho de autor y derechos conexos, UNESCO/CERLAC/ZAVALÍA, Buenos Aires, 1993. p. 66.

31 Otero Lastres, Jose Manuel, "La originalidad de las obras plásticas y las nuevas tecnologías". En: Revista Jurídica del Perú, Número 86, Año 2008, p. 408.

32 Plaza, Javier, Homenaje a Luis Rojo Ajuria: escritos jurídicos, Universidad de Cantabria, 2002. p. 481. 
Finalmente, es importante tener en cuenta, como observa Lipszyc, que el análisis de hecho en cuanto a la originalidad puede variar dependiendo de si estamos frente a un caso de reproducción no autorizada (copia idéntica) donde se alega la ausencia de originalidad $y$, por ende, ausencia de protección, o si estamos ante un caso de posible plagio que involucra dos obras distintas, con un conjunto de similitudes:

"La apreciación de la originalidad debe ser distinta en un caso de reproducción no autorizada a escala comercial (piratería) que cuando se imputa un plagio. Si se alegara que la obra no está protegida por carecer de originalidad, en el primer caso esta deberá apreciarse con criterio muy amplio, y tener en cuenta que aunque la individualidad sea mínima se satisface la exigencia. En el segundo caso se impone el criterio restrictivo y será necesario determinar si entre las dos obras existe una identidad de expresión reconocible, si ambas son, sustancialmente, una misma representación formal'133.

\section{Conclusiones.}

1. Tal como ha sido definido por la doctrina mayoritaria y por la jurisprudencia administrativa, en Derecho de Autor "originalidad" es el atributo de una obra que es el resultado del esfuerzo creativo de su autor y que refleja la impronta de su personalidad.

2. En toda obra original puede encontrarse una relación causa-efecto entre el autor (sujeto) y su obra (objeto), en la que el objeto es resultado del sujeto y, además, su reflejo. En razón de esta relación sujeto-objeto, se habla de originalidad subjetiva.

3. La existencia de la referida relación causa-efecto y la cuestión de si el objeto refleja la personalidad del sujeto son cuestiones de hecho que, por lo tanto, pueden ser determinadas de forma objetiva.

4. La originalidad no requiere ser absoluta, porque toda obra estará siempre construida sobre elementos previos.

5. El atributo de originalidad puede presentarse en distintos grados, no siendo necesario un mínimo determinado. Será suficiente el mínimo de originalidad necesario para que la obra refleje la impronta del autor.

6. La medida de la originalidad de una obra será la medida de su protección legal, es decir, del derecho de exclusividad a favor de su autor.

33 Lipszyc, Delia, Derecho de autor y derechos conexos, UNESCO/CERLAC/ZAVALÍA, Buenos Aires, 1993. p. 66. 